\title{
PERBEDAAN HASIL BELAJAR TEORI MATA PELAJARAN INSTALASI MOTOR LISTRIK DENGAN SOFTWARE ECTS DAN METODE PEMBELAJARAN KONVENSIONAL
}

\author{
${ }^{1}$ Maria Michelle Cindy, ${ }^{2}$ Purwanto Gendroyono, ${ }^{3}$ Massus Subekti \\ ${ }^{1,2,3}$ PendidikanTeknik Elektro, Fakultas Teknik, Universitas Negeri Jakarta \\ Email : amichellecindy@yahoo.com
}

\begin{abstract}
Purpose of this research to determine the effect of learning media EKTS on learning outcomes. The type of research is quantitative research, with experimental quasy method. In the study used two groups to be studied, namely the experimental group treated with the given learning media with EKTS and the other group was treated by not providing EKTS learning media. The data collection process is done by post-test in both classes. The collected data will be processed by t-test after the data meets the normal and homogeneous requirements. The results of this research, show that in the pre-test research obtained the $t_{\text {count }}<t_{\text {table }}$, that is $-2,21<2,001$ with the signification value amout $5 \%$. While, in the post-test research obtained the $t_{\text {count }}>t_{\text {table }}$, that is 4,41>2,001 with the signification value amount 5\%. Then, the $H_{o}$ is ignored and the $H_{i}$ is accepted, which means that there are some differences between the results of the post-test by the experiment class and the controlled class with the pre-test results by the experiment class and the controlled class. According to the Ttest counting results, while conclude that there are differences between the theory learning results in the installation of electrical motor subject with ECTS software and the conventional methods of learning.

Keyword : The Differences of The Theory Learning Results, ECTS Software, Conventional Learning Methods
\end{abstract}

\begin{abstract}
Abstrak
Penelitian ini bertujuan untuk mengetahui perbedaan software ECTS terhadap hasil belajar. Jenis penelitian yang digunakan adalah penelitian kuantitatif, dengan meatode quasy eksperimental. Pada penelitian digunakan dua kelompok yang akan diteliti, yakni kelompok eksperimen yang diberi perlakuan dengan diberikan media pembelajaran dengan software ECTS dan kelompok satu lagi diberi perlakuan dengan tidak memberikan media pembelajaran dengan software ECTS. Proses pengumpulan data dilakukan dengan pre-test dan post-test pada kedua kelas. Data yang telah terkumpul akan diolah dengan uji-t setelah data memenuhi persyaratan normal dan homogen.

Hasil penelitian menunjukan bahwa pada penelitian pre-test $\mathrm{t}_{\text {hitung }}<\mathrm{t}_{\text {tabel }}$, yakni $-2,21<2,001$ dengan signifikansi 5\%. Sedangkan pada penelitian post-test $t_{\text {hitung }}>t_{\text {tabel }}$, yakni 4,41 $>2,001$ dengan signifikansi $5 \%$. Maka $\mathrm{H}_{\mathrm{o}}$ ditolak dan $\mathrm{H}_{\mathrm{i}}$ diterima yang artinya terdapat perbedaan antara hasil belajar post-test kelas eksperimen dan kelas control dengan hasil belajar pre-test kelas eksperimen dan kelas kontrol. Berdasarkan hasil perhitungan uji-t, maka dapat disimpulkan bahwa terdapat perbedaan hasil belajar teori matapelajaran Instalasi Motor Listrik dengan software ECTS dan metode pembelajaran konvesional.
\end{abstract}

Kata kunci : Perbedaan Hasil Belajar Teori, Software ECTS, Metode Pembelajaran Konvensional

\section{PENDAHULUAN}

Pendidikan merupakan proses belajar mengajar yang dapat menghasilkan perubahan tingkah laku yang diharapkan dan upaya meningkatkan kualitas proses serta hasil pembelajaran dikelas. Mengingat proses pembelajaran adalah proses komunikasi maka sekolah merupakan suatu dunia komunikasi kecil tersendiri. Guru memegang kunci yang dapat mengontrol efektifitas dan efesiensi komunikasi ini.

Pada Undang-Undang Republik Indonesia Nomor 20 Tahun 2003 tentang Sistem Pendidikan Nasional menyatakan bahwa, system pendidikan nasional harus mampu menjamin pemerataan kesempatan pendidikan, peningkatan mutu serta relevansi dan efisiensi manajemen pendidikan untuk mengahadapi tantangan sesuai dengan tuntutan perubahan kehidupan lokal, nasional, dan global sehingga perlu dilakukan pembaharuan pendidikan secara terencana, terarah, dan berkesinambungan.

Mencapai hasil belajar yang maksimal untuk siswa sudah menjadi suatu harapan dan kewajiban bagi guru untuk merelisasikannya. Salah satu faktor tersebut adalah terdapat interaksi yang baik antara guru dengan siswa. Guru harus dapat menyesuaikan antara media pembelajaran dengan metode pembelajaran yang digunakan dalam memberikan pembelajaran agar siswa dapat mencapai hasil belajar yang maksimal. Media serta metode pembelajaran yang dipergunakan oleh seorang guru sangat besar peranannya terhadap 
keberhasilan kegiatan belajar mengajar. Dalam proses pembelajaran akan menjelaskan makna kegiatan-kegiatan yang dilakukan oleh guru selama pembelajaran berlangsung sehingga tujuan pembelajaran yang dilakukan dapat tercapai.

Sekolah Menengah Kejuruan (SMK) adalah salah satu sekolah yang membentuk keterampilan siswa khususnya pada keterampilan motoriknya. Karena pada umumnya, siswa lulusan SMK dipersiapkan untuk langsung terjun menghadapi dunia industri yang semakin pesat kemajuannya. Berhasil atau tidaknya siswa lulusan SMK di industri, tergantung pada seberapa besar pengetahuan dan keterampilan yang mereka dapatkan saat disekolah.

Motor listrik merupakan salah satu alat yang penting dalam pendidikan SMK, karena disetiap alat yang digunakan dalam dunia industry terdapat motor listrik. Mengingat peranan matapelajaran instalasi motor listrik yang sangat penting dan berhubungan dengan dunia industry dan kehidupan sehari-hari maka sudah seharusnya guru dan semua pihak yang terlibat dalam pembelajaran harus tepat dalam memberikan proses belajar mengajar agar pembelajaran dapat berhasil sesuai dengan yang diharapkan. Salah satu usaha yang dapat dilakukan adalah menggunakan media pembelajaran. Penggunaan media pembelajaran dapat memberikan stimulus kepada siswa dalam proses belajar, sehingga dapat meningkatkan kemampuan siswa dalam memahami ilmu pengetahuan dan mencapai hasil belajar yang maksimal.

Dalam sebuah metode pembelajaran yang ideal, guru hendaknya menyiapkan kegiatan belajar mengajar yang melibatkan mental siswa secara aktif melalui beragam kegiatan mengamati, bertanya/mempertanyakan, menjelaskan, berkomentar, mengajukan hipotesis, mengumpulkan data dan sejumlah kegiatan lainnya.

Pada pembelajaran Instalasi Motor Listrik di SMKN 5 Jakarta juga ditemukan masalah pada pembelajaran teori, dimana proses pembelajaran masih menggunakan media papan tulis dan demonstrasi sehingga siswa kurang mampu memahami cara kerja suatu rangkaian dan materi pelajaran sehingga berpengaruh terhadap rendahnya pemahaman yang membuat siswa kurang percaya diri saat praktikum.

Electrical Control Techniques Simulator (ECTS) merupakan sebuah perangkat yang dapat menstimulasikan cara kerja suatu sistem pengendalian magnetik. Penerapan media pembelajaran (ECTS) merupakan salah satu upaya untuk mengatasi masalah tersebut. Dengan ECTS siswa diharapakan agar bias mendesain dan menstimulasikan system control pengendali magnetik, dapat bereksperimen dengan berbagai macam relay, kontaktor, timer, switch dan dapat mengerti dengan jelas system rangkaian yang mereka buat.

Berdasarkan latar belakang masalah yang telah dipaparkan, maka peneliti ingin mengetahui perbandingan hasil belajar teori matapelajaran instalasi motor listrik dengan media pembelajaran ECTS dan Konvensional di SMKN 5 Jakarta.

\section{METODE}

Populasi pada penelitian ini yaitu seluruh siswa Kelas XI Jurusan kelistrikan SMK Negeri 5 Jakarta yang terdaftar pada tahun 2017/2018 yang berjumlah 90 siswa yang terdiri atas tiga kelas. Masing-masing kelas memiliki jumlah yang kurang lebih sama pada kelas XI-TITL 1 terdiri atas 34 siswa, kelas XI-TITL 2 terdiri atas 34 siswa dan pada kelas XI-TITL 3 terdiri atas 22 siswa.

Pengambilan sample pada penelitian ini yaitu teknik simple random sampling. Simple random sampling digunakan untuk menentukan kelas mana yang akan dijadikan sebagai kelas eksperimen dan kelas mana yang akan dijadikan sebagai kelas kontrol . Cara yang dilakukan adalah dengan membuat undian pada kertas. Pertama, peneliti menuliskan nama masingmasing kelas pada dua buah kertas kosong. Kemudian, peneliti melipat kertas dan mengocok kertas yang telah dilipat. Kertas pertama yang keluar dijadikan sebagai kelas eksperimen dan kelas yang tidak keluar dalam kocokan akan dijadikan sebagai kelas kontrol. Setelah dilakukan pengocokan, didapatkan kelas XI TITL 1 sebagai kelas kontrol dan kelas XI TITL 2 sebagai kelas eksperimen. 
Pada penelitian, uji validitas menggunakan rumus korelasi product moment dengan angka kasar, sedangkan untuk uji reliabilitas digunakan rumus Spearman-Brown. Selanjutnya, uji prasyarat analisis digunakan uji lilifors untuk melihat normalitas dan uji fisher untuk melihat homogenitas. Dalam penelitian, untuk menguji hipotesis digunakan uji-t dengan taraf kesalahan $5 \%$.

\section{HASIL DAN PEMBAHASAN \\ Hasil Belajar Kelas Kontrol}

Jumlah sampel yang di gunakan pada kelas kontrol, yakni pembelajaran yang tidak menggunakan software ECTS adalah 30 siswa dengan perolehan nilai pre test minimal adalah 45,7 dan nilai maksimal adalah 74,3. Dari data tersebut dengan menggunakan statistika untuk mendapatkan kelas interval diperoleh banyak kelas sejumlah 5 dengan interval 6 yang merupakan interval yang dapat digunakan untuk membuat daftar distribusi data dan perhitungan lengkap dapat dilihat pada lampiran Sedangkan rangkuman hasil distribusi data dapat dilihat pada tabel 1. dibawah ini:

Tabel 1 Distribusi Frekuensi Data Pre-Test Hasil Belajar Instalasi Motor Listrik

\begin{tabular}{ccccc}
\hline $\begin{array}{c}\text { Kelas } \\
\text { Interval }\end{array}$ & Batas Kelas & $\begin{array}{c}\text { Tanda } \\
\text { Kelas }\end{array}$ & $\begin{array}{c}\text { Frekuensi } \\
\text { Absolut }\end{array}$ & $\begin{array}{c}\text { Frekuensi } \\
\text { Relatif }\end{array}$ \\
\hline $46-50$ & $45,5-50,5$ & 48 & 3 & $10 \%$ \\
$51-55$ & $51,5-55,5$ & 53 & 4 & $13,33 \%$ \\
$56-60$ & $56,5-60,5$ & 58 & 5 & $16,67 \%$ \\
$61-65$ & $61,5-65,5$ & 63 & 8 & $26,66 \%$ \\
$66-70$ & $66,5-70,5$ & 68 & 6 & $20,00 \%$ \\
$71-75$ & $71,5-75,5$ & 73 & 4 & $13,33 \%$ \\
& Jumlah & & 30 & $100 \%$ \\
\hline
\end{tabular}

Sumber : Data Penelitian 2018

Berdasarkan daftar distribusi frekuensi nilai pre-test di atas dapat diketahui bahwa pada kelas kontrol, siswa paling banyak memperoleh nilai dengan rentang antara 61 hingga 65 , hal ini dapat dilihat dari total frekuensi relatif pada rentang tersebut adalah 26,6\% atau sejumlah 8 0siswa. Sedangkan, berdasarkan frekuensi relatif dan absolut, nilai dengan rentang paling kecil, yakni antara 46 hingga 50 diperoleh 3 siswa atau sejumlah $10 \%$. Dari tabel daftar distribusi yang tertera dapat diketahui bahwa terdapat antara 20siswa yang tidak tuntas nilai nya berdasarkan KKM, yakni siswa yang memperoleh nilai dengan rentang antara 46 hingga 50 sampai 61 hingga 65. Kesimpulan dari tabel distribusi frekuensi nilai pre-test di atas dapat dilihat pada gambar 1 sebagai berikut:

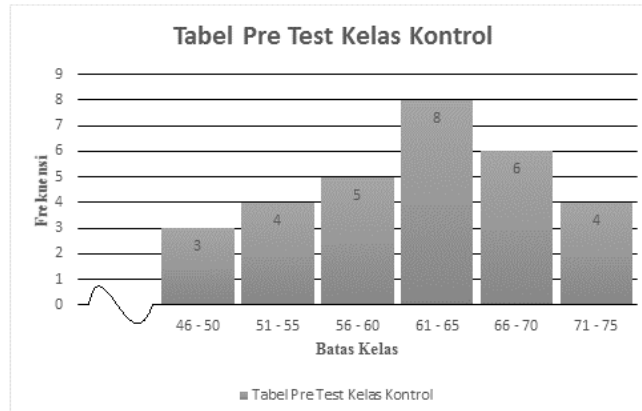

Gambar 1. Histogram Hasil Belajar Hasil Belajar Pre-TestInstalasi Motor Listrik Kelas Kontrol

Berdasarkan histogram diatas terlihat bahwa histogram berbentuk lembah dengan puncak lembah berada pada rentang 61 - 65 dengan jumlah frekuensi 8. Pada histogram juga tergambar siswa paling sedikit yakni berjumlah 3 siswa memperoleh nilai dengan rentang antara 46 hingga 50. Sedangkan siswa yang memperoleh nilai dengan rentang antara 51 sampai 55 diperoleh oleh 4 siswa, nilai dengan rentang antara 56 - 60 diperoleh oleh 5 siswa, nilai dengan rentang antara 66 - 70 diperoleh oleh 6 siswa, dan nilai dengan rentang antara 71 - 75 diperoleh oleh 4 siswa.

\section{Hasil Belajar Kelas Eksperimen}

Jumlah sampel yang di gunakan pada kelas eksperimen, yakni pembelajaran menggunakan software ECTS adalah 30 siswa dengan perolehan nilai pre-test minimal adalah 42,9, nilai maksimal adalah 68,6. Dari data tersebut dengan menggunakan statistika untuk mendapatkan kelas interval diperoleh banyak kelas sejumlah 5 dengan interval 6 yang merupakan interval yang dapat digunakan untuk membuat daftar distribusi data dan perhitungan lengkap dapat dilihat pada lampiran. Sedangkan hasil distribusi data dapat dilihat pada tabel 2 . dibawah ini:

Tabel 2. Distribusi Frekuensi Data Pre-Test Hasil Belajar Instalasi Motor Listrik Kelas Eksperimen

\begin{tabular}{ccccc}
\hline $\begin{array}{c}\text { Kelas } \\
\text { Interval }\end{array}$ & Batas Kelas & $\begin{array}{c}\text { Tanda } \\
\text { Kelas }\end{array}$ & $\begin{array}{c}\text { Frekuensi } \\
\text { Absolut }\end{array}$ & $\begin{array}{c}\text { Frekuensi } \\
\text { Relatif }\end{array}$ \\
\hline $43-47$ & $42,5-47,5$ & 45 & 3 & $10 \%$ \\
$48-52$ & $48,5-52,5$ & 50 & 5 & $16,66 \%$ \\
$53-57$ & $53,5-57,5$ & 55 & 6 & $20 \%$ \\
$58-62$ & $58,5-62,5$ & 60 & 7 & $23,33 \%$ \\
$63-67$ & $63,5-67,5$ & 65 & 5 & $16,66 \%$ \\
$68-72$ & $68,5-72,5$ & 70 & 4 & $13,33 \%$ \\
& Jumlah & & 30 & $100 \%$ \\
\hline
\end{tabular}

Sumber : Data Penelitian 2018

Berdasarkan daftar distribusi frekuensi nilai pre-test di atas dapat diketahui bahwa pada kelas eksperimen, siswa paling banyak memperoleh nilai dengan rentang antara 58 hingga 62 , hal ini 
dapat dilihat dari total frekuensi relatif pada rentang tersebut adalah 23,33\% atau sejumlah 7 siswa. Sedangkan, berdasarkan frekuensi relatif dan absolut, nilai dengan rentang paling kecil, yakni antara 43 hingga 47 yang diperoleh oleh 3 siswa atau sejumlah 10\%. Dari tabel daftar distribusi yang tertera dapat diketahui bahwa terdapat 23 siswa yang tidak tuntas nilai nya berdasarkan KKM. Kesimpulan dari tabel distribusi frekuensi nilai post-test di atas dapat dilihat pada gambar 2 sebagai berikut:

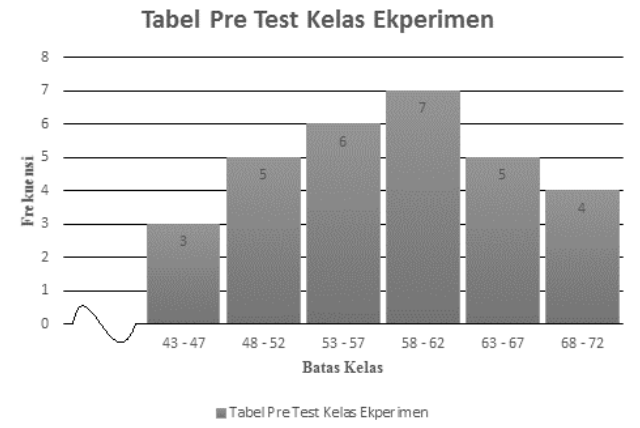

Gambar 2 Histogram Hasil Belajar Pre-TestInstalasi Motor Listrik Kelas Eksperimen

Berdasarkan histogram diatas terlihat bahwa histogram berbentuk lembah dengan puncak lembah berada pada rentang 58 - 62 dengan jumlah frekuensi 7. Pada histogram juga tergambar siswa paling sedikit yakni berjumlah 3 siswa memperoleh nilai dengan rentang antara 43 hingga 47 . Sedangkan untuk hasil yang lain, siswa yang memperoleh nilai dengan rentang antara 48 - 52 diperoleh oleh 5siswa, nilai dengan rentang antara 53 - 57 diperoleh oleh 6 siswa, nilai dengan rentang antara 63 - 67 diperoleh oleh 5 siswa dan nilai dengan rentang 68 - 72 diperoleh oleh 4 siswa.

\section{Hasil Belajar Post-Test Instalasi Motor Listrik \\ Hasil Belajar Kelas Kontrol}

Sampel yang digunakan pada kelas kontrol, adalah yang tidak menggunakan ECTS adalah 30 siswa dengan perolehan nilai post test minimal adalah 57,1 dan nilai maksimal adalah 85,7. Dari data tersebut dengan menggunakan statistika untuk mendapatkan kelas interval diperoleh banyak kelas sejumlah 5 dengan interval 6 yang merupakan interval yang dapat digunakan untuk membuat daftar distribusi data dan perhitungan lengkap dapat dilihat pada lampiran. Rangkuman hasil distribusi data dapat dilihat pada tabel 3:
Tabel 3 Distribusi Frekuensi Data Post-Test Hasil Belajar Instalasi Motor Listrik

\begin{tabular}{ccccc}
\hline $\begin{array}{c}\text { Kelas } \\
\text { Interval }\end{array}$ & Batas Kelas & $\begin{array}{c}\text { Tanda } \\
\text { Kelas }\end{array}$ & $\begin{array}{c}\text { Frekuensi } \\
\text { Absolut }\end{array}$ & $\begin{array}{c}\text { Frekuensi } \\
\text { Relatif }\end{array}$ \\
\hline $57-62$ & $56,5-62,5$ & 59 & 3 & $10 \%$ \\
$62-66$ & $62,5-66,5$ & 64 & 5 & $16,66 \%$ \\
$67-71$ & $67,5-71,5$ & 69 & 8 & $26,66 \%$ \\
$72-76$ & $72,5-76,5$ & 74 & 6 & $20 \%$ \\
$77-81$ & $77,5-81,5$ & 79 & 5 & $16,6 \%$ \\
$82-86$ & $81,5-86,5$ & 84 & 3 & $10 \%$ \\
& Jumlah & & 30 & $100 \%$ \\
\hline
\end{tabular}

Sumber : Data Penelitian 2018

Berdasarkan daftar distribusi frekuensi nilai post-test di atas dapat diketahui bahwa pada kelas kontrol, siswa paling banyak memperoleh nilai dengan rentang antara 67 hingga 71, hal ini dapat dilihat dari total frekuensi relatif pada rentang tersebut adalah $26,6 \%$ atau sejumlah 8 siswa. Sedangkan, berdasarkan frekuensi relatif dan absolut, nilai dengan rentang paling kecil, yakni antara 57 hingga 61 diperoleh 3 siswa atau sejumlah $10 \%$. Dari tabel daftar distribusi yang tertera dapat diketahui bahwa terdapat antara 6siswa yang tidak tuntas nilai nya berdasarkan KKM, yakni siswa yang memperoleh nilai dengan rentang antara 57 hingga 61 atau 62 hingga 66. Kesimpulan dari tabel distribusi frekuensi nilai post-test di atas dapat dilihat pada gambar 3 sebagai berikut:

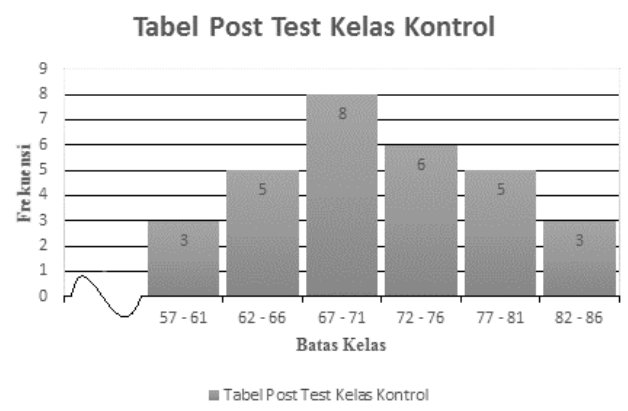

Gambar 3. Histogram Hasil Belajar Hasil Belajar PostTest Instalasi Motor Listrik

Berdasarkan histogram diatas terlihat bahwa histogram berbentuk lembah dengan puncak lembah berada pada rentang 66 - 71 dengan jumlah frekuensi 8. Pada histogram juga tergambar siswa paling sedikit yakni berjumlah 3 siswa memperoleh nilai dengan rentang antara 57 hingga 61. Sedangkan siswa yang memperoleh nilai dengan rentang antara 62 sampai 66 diperoleh oleh 5 siswa, nilai dengan rentang antara 72 - 76 diperoleh oleh 6 siswa, nilai dengan rentang antara 77 - 81 diperoleh oleh 5 siswa, dan nilai dengan rentang antara 82 - 86 diperoleh oleh 3 siswa. 


\section{Hasil Belajar Kelas Eksperimen}

Jumlah sampel yang di gunakan pada kelas eksperimen, yakni pembelajaran menggunakan software ECTS adalah 30 siswa dengan perolehan nilai post test minimal adalah 65,7 , nilai maksimal adalah 91,4. Dari data tersebut dengan menggunakan statistika untuk mendapatkan kelas interval diperoleh banyak kelas 5 dengan interval 6 yang merupakan interval yang dapat digunakan untuk membuat daftar distribusi data dan perhitungan lengkap dapat dilihat pada lampiran. Hasil distribusi data dapat dilihat pada tabel 4 dibawah ini:

Tabel 4 Distribusi Frekuensi Data Post-Test Hasil

Belajar Instalasi Motor Listrik Kelas Eksperimen

\begin{tabular}{ccccc}
\hline $\begin{array}{c}\text { Kelas } \\
\text { Interval }\end{array}$ & Batas Kelas & $\begin{array}{c}\text { Tanda } \\
\text { Kelas }\end{array}$ & $\begin{array}{c}\text { Frekuensi } \\
\text { Absolut }\end{array}$ & $\begin{array}{c}\text { Frekuensi } \\
\text { Relatif }\end{array}$ \\
\hline $66-70$ & $65,5-70,5$ & 68 & 2 & $6,6 \%$ \\
$71-75$ & $70,5-75,5$ & 73 & 4 & $13,3 \%$ \\
$76-80$ & $75,5-80,5$ & 78 & 9 & $30 \%$ \\
$81-85$ & $80,5-85,5$ & 83 & 7 & $23,3 \%$ \\
$86-90$ & $85,5-91,5$ & 88 & 5 & $16,6 \%$ \\
$91-95$ & $91,5-96,5$ & 93 & 3 & $10 \%$ \\
\multicolumn{5}{c}{ Jumlah } \\
\hline
\end{tabular}

Sumber : Data Penelitian 2018

Berdasarkan daftar distribusi frekuensi nilai post-test di atas dapat diketahui bahwa pada kelas eksperimen, siswa paling banyak memperoleh nilai dengan rentang antara 76 hingga 80, hal ini dapat dilihat dari total frekuensi relatif pada rentang tersebut adalah 30 $\%$ atau sejumlah 9 siswa. Sedangkan, berdasarkan frekuensi relatif dan absolut, nilai dengan rentang paling kecil, yakni antara 66 hingga 70 yang diperoleh oleh 2 siswa atau sejumlah 6,66\%. Dari tabel daftar distribusi yang tertera dapat diketahui bahwa tidak terdapat siswa yang tidak tuntas nilai nya berdasarkan KKM. Kesimpulan dari tabel distribusi frekuensi nilai post-test di atas dapat dilihat pada gambar 4 sebagai berikut:

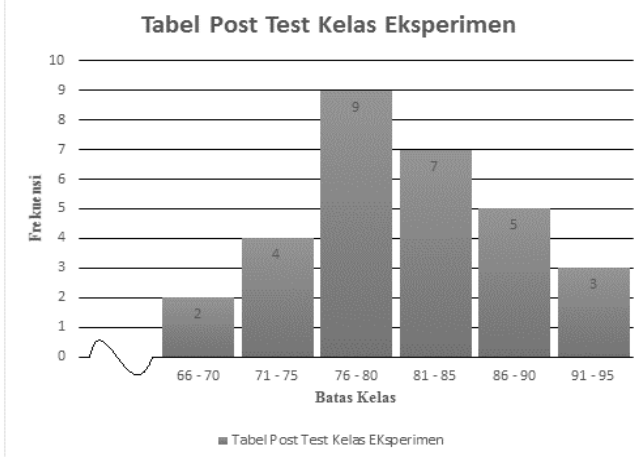

Gambar 4.4 Histogram Hasil Belajar Post-TestInstalasi Motor ListrikKelas Eksperimen
Berdasarkan histogram diatas terlihat bahwa histogram berbentuk lembah dengan puncak lembah berada pada rentang 74 - 79 dengan jumlah frekuensi 8. Pada histogram juga tergambar siswa paling sedikit yakni berjumlah 2 siswa memperoleh nilai dengan rentang antara 62 hingga 67. Sedangkan untuk hasil yang lain, siswa yang memperoleh nilai dengan rentang antara 68 - 73 diperoleh oleh 5siswa, nilai dengan rentang antara 80 - 85 diperoleh oleh 7 siswa, nilai dengan rentang antara 86 - 91 diperoleh oleh 5 siswa dan nilai dengan rentang 92 - 97 diperoleh oleh 3 siswa.

\section{Hasil Pengujian Normalitas}

Normalitas pada hasil post-test dilakukan dengan menggunakan uji lillifors dengan taraf signifikasi $\alpha=0,05$. Dari hasil perhitungan normalitas pada kelas kontrol diperoleh nilai $\mathrm{L}_{\text {hitung }}=0,0787$, sedangkan $\mathrm{L}_{\text {tabel }(0,05)}=0,161$. Jadi Lhitung $<\mathrm{L}_{\text {tabel}}$, maka $\mathrm{H}_{\mathrm{o}}$ diterima.

Dari hasil perhitungan normalitas pada kelas eksperimen diperoleh nilai $L_{\text {hitung }}=0,0942$, sedangkan $\mathrm{L}_{\text {tabel }(0,05)}=0,161$. Jadi $\mathrm{L}_{\text {hitung }}<\mathrm{L}_{\text {tabel }}$, maka $\mathrm{H}_{\mathrm{o}}$ diterima. Maka dari itu, disimpulkan data siswa yang tidak menggunakan software ECTSberdistribusi normal. Untuk perhitungan lengkap dapat dilihat pada lampiran.

\section{Hasil Pengujian Homogenitas}

Pengujian homogenitas untuk hasil post-test dilakukan terhadap siswa yang menggunakan software ECTSdengan yang tidak menggunakan, dilakukan menggunakan uji Fisher dengan taraf signifikan 0,05.Dari hasil perhitungan didapatkan $F_{\text {hitung }}<F_{\text {tabel }}$ atau $1,17<4,02$. Artinya dari perhitungan ini dapat disimpulkan populasi kelas kontrol dan kelas eksperimen berasal dari variansi yang homogen. Uji Hipotesis

Berdasarkan hasil perhitungan, untuk perhitungan uji $\mathrm{t}$ post-test diperoleh nilai $t_{\text {hitung }}=4,41$ dan $\quad t_{\text {tabel }}=2,042$, untuk derajat kebebasan 58 dengan taraf signifikansi $5 \%$. Berdasarkan kreteria pengujian yang digunakan karena $\mathrm{t}_{\text {hitung }}>\mathrm{t}_{\text {tabel }}$, maka $\mathrm{H}_{\mathrm{o}}$ ditolak dan $\mathrm{H}_{\mathrm{i}}$ diterima yang artinya terdapat perbedaan hasil belajar teori mata pelajaran Instalasi Motor Listrik dengan software ECTS dan konvesional. Berdasarkan hal tersebut, maka dapat disimpulkan bahwa terdapat perbedaan hasil 
belajar teori mata pelajaran Instalasi Motor Listrik dengan software ECTS dan konvesional.

\section{KESIMPULAN DAN SARAN \\ Kesimpulan}

Hasil penelitian yang telah dilakukan menunjukan terjadi peningkatan hasil rata-rata nilai dari pre-test ke post-test di dalam kelas eksperimen dan kelas kontrol. Pada hasil perhitungan nilai pre-test kelompok eksperimen didapatkan rata-rata nilai sebesar 57,04 dengan nilai terendah 42,9 dan nilai tertingginya sebesar 68,6 . Hasil perhitungan kelas control didapatkan rata-rata nilai sebesar 61,3 dengan nilai terendahnya sebesar 45,7 dan tertingginya adalah 74,3 .

Pada hasil perhitungan post-test kelompok eksperimen didapatkan rata-rata nilai sebesar 80,6 , dengan nilai terendahnya sebesar 65,7 dan nilai tertingginya sebesar 91,4. Hasil perhitungan post-test kelompok kontrol didapatkan nilai rata-rata sebesar 71,5, dengan nilai terendahnya adalah 57,1 dan tertingginya adalah 85,7. Hasil perhitungan hipotesis penelitian pre-test menunjukan $\mathrm{t}_{\text {hitung }}<\mathrm{t}_{\text {tabel }}$, yakni $-2,21<2,042$. Sedangkan hasil perhitungan hipotesis penelitian post-test menunjukan $t_{\text {hitung }}>\mathrm{t}_{\text {tabel }}$, yakni 4,97 $>2,042$. Berdasarkan data-data diatas, dapat disimpulkan bahwa terdapat perbedaan hasil belajar teori instalasi motor listrik dengan software EKTS dan metode pembelajaran konvensional.

\section{Saran}

Berdasarkan hasil penelitian yang telah dicapai, maka disarankan penggunaan software ECTS sebagai media pembelajaran, dimana dalam penggunaannya siswa lebih paham dan mendapatkan wawasan secara langsung mengenai teori yang memerlukan pengaplikasian langsung sehingga dapat mempengaruhi hasil belajar siswa.

\section{DAFTAR PUSTAKA}

Aunurrahman. (2013). Belajar dan Pembelajaran. Bandung: Alfabeta.

Bintoro, A. G. (2000). Dasar-Dasar Pekerjaan Las . Yogyakarta: Kanisius.
Creswell, John. W. 1994. Reserch Design Qualitative \& Quantitative Approaches. California: Sage Publications.

Fajri Ismail. (2014). EvaluasiPendidikan. (Palembang:TunasGemilang Press)

Haris, A. J. (2012). Evaluasi Pembelajaran. Yogyakarta: Multi Presindo.

Jihad, H. d. (2012). Evaluasi Pembelajaran. Yogyakarta: Multi Pressindo.

Liklikwatil, Y. (2014). Mesin-mesin Listrik untuk Program D3. Sleman: deepublish.

Munadi, Y. (2010). Media Pembelajaran; Sebuah Pendekatan Baru. Jakarta: Gaung Persada (GP) Press.

Munadi, Y. (2013). Media Pembelajaran. Jakarta:Referensi.

Nurcahyo, P. A. (2016). Pengaruh Penggunaan Media Pembelajaran Terhadap Hasil Belajar Siswa Mata Pelajaran Kelistrikan Mesin \& Konversi Energi di SMK N 2 Depok.

NurHamiyah, Muhammad Jauhar. (2014). StrategiBelajar-Mengajar Di Kelas. Jakarta: PrestasiPustakarya

Purwanto.(2010). Metodologi Penelitian Kuantitatif. Yogyakarta: PustakaPelajar

Purwanto. (2013). Evaluasi Hasil Belajar. Yogyakarta: Pustaka Belajar.

Rifa'i, C. A. (2012). Psikologi Pendidikan. Semarang: Universitas Negeri Semaran Press.

Sanaky, A. (2013). Media Pembelajaran Interaktif-Inovatif. Yogyakarta: Kaukuba Dipantara.

Sanjaya, W. (2008). Strategi Pembelajaran Berorientasi Standar Proses Pendidikan. Jakarta: Kencana Prenada Media Group.

Soenarto. 1987. Teknik Sampling. Jakarta: P2LPTK.

Sugiyono. (2010). Metode Penelitian Pendidikan Pendekatan Kuantitatif, Kualitatif dan RnD. Bandung: Alfabeta.

Sugiyono. (2011). Metode Penelitian Kuantitatif, Kualitatif dan R\&D. Jakarta: Alfabeta. Suryabrata, S. (1994). Masalah Sosial dan Pembangunan. Jakarat: PT Dunia Pustaka.

Susanto, A. (2013). Teori Belajar dan Pembelajaran di Sekolah Dasar. Jakarta: PT. Kharisma Putra Utama 